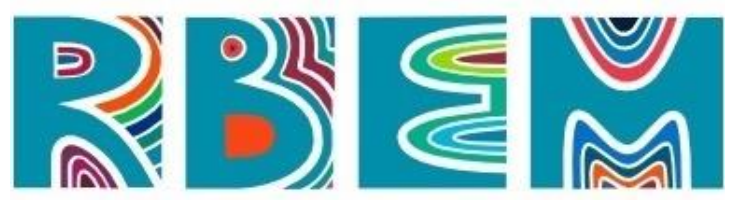

REVISTA BAIANA dE EDUCAÇÃo MATEMÁtICA

ARTIGO

https://doi.org/10.47207/rbem.v2i01.12392

\title{
O ESTÁGIO CURRICULAR SUPERVISIONADO NA COMPREENSÃO DE LICENCIANDOS: PERSPECTIVAS, DESAFIOS E APRENDIZAGENS
}

\author{
FELCHER, Carla Denize Ott \\ Universidade Federal de Pelotas - UFPel. Doutora em Educação em Ciências. \\ ORCID: https://orcid.org/0000-0002-9733-9451. E-mail: carlafelcher@gmail.com \\ FERREIRA, André Luis Andrejew \\ Universidade Federal de Pelotas - UFPel. Doutor em Informática na Educação. \\ ORCID: https://orcid.org/0000-0001-6353-4665. E-mail: andrejew.ferreira@gmail.com.
}

\begin{abstract}
Resumo: O presente artigo tem por objetivo apresentar e analisar as perspectivas e os desafios compreendidos por estagiários que vivenciaram as experiências do Estágio Curricular Supervisionado, assim como as aprendizagens nelas construídas. Trata-se de uma investigação predominantemente qualitativa, com análise de questionários pré-estágio e pós-estágio, ambos com questões abertas e também análise de portfólios virtuais construídos pelos estagiários ao longo do período de estágio. Os dados produzidos apontam que, entre perspectivas e desafios, os estagiários citaram: aprendizagem matemática por parte dos estudantes; organização, planejamento e uso de metodologias diversificadas. Em relação às aprendizagens construídas, lidar com os imprevistos foi a mais citada. Por fim, os estagiários consideram a experiência significativa e de grandes aprendizagens, contribuindo para reafirmar a escolha profissional, ou seja, ser professor de Matemática.
\end{abstract}

Palavras-chave: Estágio curricular. Prática docente. Formação inicial. Professor de Matemática.

\section{THE SUPERVISED CURRICULAR INTERNSHIP IN THE UNDERSTANDING OF UNDERGRADUATE: PERSPECTIVES, CHALLENGES AND LEARNING}

\begin{abstract}
This article aims to present and analyze the perspectives and challenges understood by interns who have lived the Supervised Internship experiences, as well as the learning built on them. It is a predominantly qualitative investigation, with analysis of pre-internship and post-internship questionnaires, both with open questions, and also analysis of virtual portfolios built by the interns during the internship period. The data produced show that, among perspectives and challenges, the interns mentioned: mathematical learning by students; organization, planning and use of diversified methodologies. In relation to constructed learning, dealing with the unforeseen was the most mentioned. At last, the interns consider the experience significant and of great learning, contributing to reaffirm their professional choice, i.e., to be a Mathematics teacher.
\end{abstract}

Keywords: Curricular stage. Teaching practice. Initial formation. Maths teacher. 


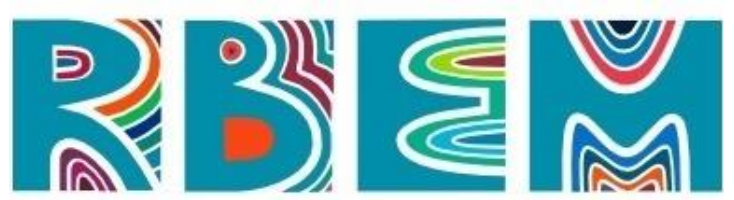

REVISTA BAIANA DE EDUCAÇÃO MATEMÁTICA

\title{
LAS PRÁCTICAS CURRICULARES SUPERVISADAS EN LA COMPRENSIÓN DE LICENCIATARIOS: PERSPECTIVAS, RETOS Y APRENDIZAJE
}

\begin{abstract}
Resumen: Este artículo tiene como objetivo presentar y analizar las perspectivas y desafíos comprendidos por los pasantes que han vivido las experiencias de la Pasantía Curricular Supervisada, así como el aprendizaje construido sobre ellas. Se trata de una investigación predominantemente cualitativa, con análisis de cuestionarios previos y posteriores a la pasantía, ambos con preguntas abiertas, y también análisis de los portafolios virtuales construidos por los pasantes durante el período de pasantía. Los datos producidos muestran que, entre perspectivas y desafíos, los pasantes mencionaron: aprendizaje matemático por parte de los estudiantes; organización, planificación y uso de metodologías diversificadas. En relación al aprendizaje construido, lidiar con lo imprevisto fue lo más mencionado. Finalmente, los pasantes consideran significativa la experiencia y de gran aprendizaje, contribuyendo a reafirmar su elección profesional, es decir, ser docente de Matemáticas.

Palavras-Clave: Etapa curricular. Práctica docente. Formación inicial. Profesor de matemáticas.
\end{abstract}

\section{Introdução}

Qual criança nunca brincou de "escolinha"? E qual nunca quis ser o professor na brincadeira? Esses questionamentos, que parecem tão ingênuos, remetem-nos a uma situação importante e plausível de atenção. O "brincar de escolinha" e o de "ser professor" têm se resumido a brincadeiras infantis, porquanto a realidade é diferente e preocupante, ainda que o trabalho dos professores tenha papel central do ponto de vista político e cultural, pois há dois séculos constitui a forma dominante de socialização e de formação nas sociedades modernas e continua se expandindo (GATTI; SÁ BARRETO, 2009).

Ser professor no Brasil não tem sido uma tarefa fácil, principalmente a partir da metade do século XX e mais acentuadamente nos últimos anos (FREITAS et al., 2005). Segundo os autores, entre os fatores que justificam essa afirmativa, destaca-se: 1) as exigências cada vez maiores em relação ao trabalho dos professores, tendo em vista o desenvolvimento das tecnologias digitais e o do mundo do trabalho; 2) as políticas públicas de educação decorrentes de modelos neoliberais que promovem reformas padronizadas (FREITAS et al. 2005).

Nesse contexto, não raramente, os docentes sofrem críticas e, particularmente, o professor de Matemática, como afirmava Fiorentini (2003), é o que mais sofria esse julgamento ou avaliação negativa. Os formadores dos professores de Matemática são acusados com frequência de não proporcionarem uma efetiva formação, capaz de romper com 


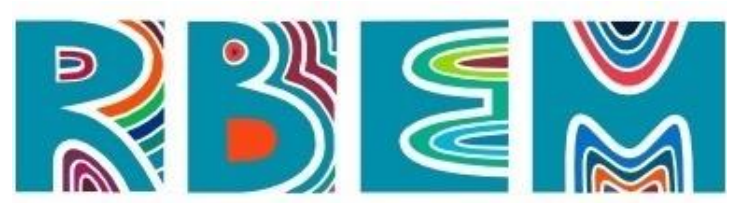

REVISTA BAIANA DE EDUCAÇÃO MATEMÁTICA

a tradição pedagógica (FIORENTINI, 2003). Assim, consoante o autor, os professores de Matemática são acusados de dar continuidade à mesma metodologia, resistindo às inovações, o que não é verdade, devido ao expressivo número de inovações e discussões na formação inicial (FIORENTINI, 2003).

Todas essas discussões demandam ser revisitadas e consideradas quando se pensa na formação inicial do professor e em especial no Estágio Curricular Supervisionado (ECS), requisito obrigatório para atuar na Educação Básica, conforme a legislação brasileira (BRASIL, 1996). Além de obrigatório, o ECS é um “[...] momento especial do processo de formação do professor em que ocorre de maneira mais efetiva a transição, ou a passagem de aluno a professor" (FIORENTINI; CASTRO, 2003, p. 122).

O primeiro contato com a sala de aula, para uma parcela significativa dos discentes, é o ECS. Não raras as vezes, é permeado de dificuldades, dúvidas, anseios e expectativas, mas também de prática na futura profissão. Diante do exposto, o objetivo deste artigo é apresentar e analisar as perspectivas e os desafios compreendidos por estagiários que vivenciaram as experiências do Estágio Curricular Supervisionado, assim como as aprendizagens nelas construídas. Trata-se de um estudo predominantemente qualitativo, com análise de questionário inicial e pós-estágio e, também, de portfólios virtuais produzidos pelos acadêmicos ao longo do período do estágio.

Segundo Lopes et al. (2017), o ECS é uma etapa importante para a formação do futuro professor, porém, de acordo com Silva e Oliveira (2021), o pouco valor a ele concedido se mostra visível na pequena quantidade de pesquisas sobre o tema na área de educação matemática. Tais afirmativas justificam a necessidade desta pesquisa, que se destaca por trazer perspectivas, desafios e aprendizagens dos estagiários da Licenciatura em Matemática, o que não é comum, já que alguns textos optam pelos desafios e outros pelas aprendizagens. No entanto, entende-se que a complexidade da prática de estágio permite abordar as três questões de modo relacionado e articulado à formação docente.

Diante desse cenário, a escrita desta pesquisa investiga apresentar e analisar as perspectivas e os desafios compreendidos por estagiários que vivenciaram as experiências do Estágio Curricular Supervisionado, assim como as aprendizagens nelas construídas O artigo apresenta a abordagem teórica na qual a pesquisa se baliza e o percurso metodológico da produção e análise dos dados. Por fim, há os resultados, as discussões e as considerações 


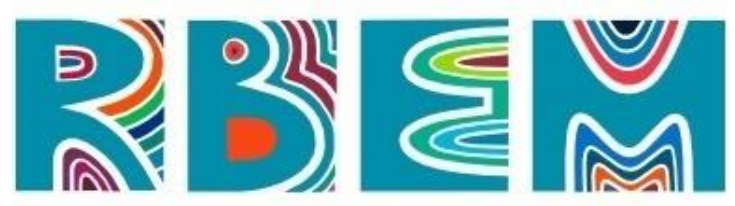

finais sobre o estágio obrigatório.

\section{Referencial teórico}

O ECS representa a inserção do professor em formação no campo da prática profissional, geralmente pela primeira vez. É o momento de observar, registrar, participar, problematizar, trocar ideias, conhecer o ambiente escolar e sua organização, construir conhecimento e interagir com professores e estudantes (FILLOS; MARCON, 2011). Corroborando o exposto, Lopes et al. (2017) citam que esse é um momento privilegiado da formação, haja vista que possibilita desenvolver a criatividade, construir novas aprendizagens e saberes relacionando teoria e prática.

A Resolução $\mathrm{CNE} / \mathrm{CP} \mathrm{n}^{\mathrm{o}}$ 2, de 2015, em relação à carga horária dos ECS, salienta que são 400 (quatrocentas) horas, na área de formação e atuação na educação básica, contemplando também outras áreas específicas, se for o caso, conforme o projeto de curso da instituição (BRASIL, 2015). A resolução em tela assevera que o ECS é componente obrigatório da organização curricular das licenciaturas, sendo uma atividade específica intrinsecamente vinculada à prática e às demais atividades de trabalho acadêmico (BRASIL,

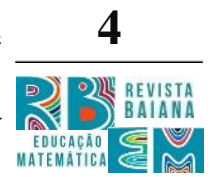
2015).

Para Lopes et al. (2017), o ECS é uma etapa complementar à formação do licenciando, que deve estar presente em todo o processo de formação, articulando teoria e prática. Nesse sentido,

O Estágio Supervisionado não pode se configurar como espaço isolado, fechado em si mesmo e desarticulado do restante do curso, mas sim como espaço em que os professores em formação vão colocando em uso os conhecimentos que aprendem, ao mesmo tempo em que possam mobilizar outros, de diferentes naturezas e oriundos de diferentes experiências, nos diferentes tempos e espaços curriculares (SBEM, 2003, p. 22).

O entendimento de que o ECS não é uma etapa isolada ao final do curso, mas sim um momento de relacionar saberes e prática, mobilizando as diferentes aprendizagens construídas ao longo do processo, tem relação com o exposto por Fazenda (2012). A autora cita que o ECS precisa estar conectado a todas as disciplinas que compõem a formação de professores, considerado a complexidade e a importância do momento. 


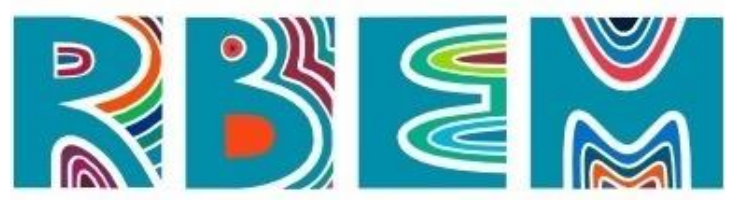

REVISTA BAIANA DE EDUCAÇÃO MATEMÁTICA

No complexo contexto do ECS, uma crítica comum tecida pelos professores em serviço, segundo Ponte (2002), é que os estagiários não chegam às escolas devidamente preparados para a prática. Entende-se que esse momento é também de aprender, ou seja, um processo normal de crescimento do acadêmico. O estágio é um espaço de revisão do fazer pedagógico, que coloca o acadêmico na realidade do sistema educacional, permitindo que o mesmo transite pelas Instituições de Ensino Superior, pelas Escolas e Secretarias de Educação. Ademais,

O contato gradativo e sistemático com o futuro campo de trabalho, com as situações escolares em diferentes níveis de ensino, ao longo de todo curso de formação inicial, pode possibilitar ao futuro professor reconhecer limites e potencialidades das práticas educativas observadas; analisar, construir e testar possíveis ações para remediar ou suprir as necessidades práticas com as quais entrará em contato em sua futura prática profissional (CYRINO; PASSERINI, 2009, p. 126).

Em Fiorentini e Castro (2003) encontra-se a experiência do estagiário Allan, o qual foi revendo e modificando sua prática ao longo do estágio e, assim, concluiu esse importante momento com êxito e muitas aprendizagens. Consoante os autores, o momento de reflexão foi fundamental para que ele percebesse a complexidade da arte de ensinar e que poderia modificar sua prática. O referido caso ilustra que a academia não é lugar unicamente da produção de conhecimento e a escola da reprodução. Ao contrário, “[...] na realização do trabalho pedagógico que os saberes da profissão docente são efetivamente compreendidos, produzidos ou ressignificados" (FIORENTINI; CASTRO, 2003, p. 151-152).

A escola é uma instituição com inúmeras particularidades, mas igualmente complexa. Com isso, é de se pensar se a formação inicial deve buscar inserir os acadêmicos no formato escolar existente, ou deve voltar-se a contribuir para que a escola seja transformada. Ponte (2000) trata essa discussão como um dilema difícil de resolver. Se a formação não preparar o jovem professor para se inserir nas escolas que existem, com os seus alunos e as suas culturas profissionais, corre o sério risco de formar inaptos para desempenhar o papel. Porém, se a formação não preparar os novos docentes para a mudança educativa e social, assume-se como mais uma força conservadora e, no fundo, complacente com os problemas existentes (PONTE, 2002).

A complexidade e as particularidades que envolvem a escola e se relacionam aos estágios merecem atenção. Não é raro um estagiário receber um não para o seu pedido de 


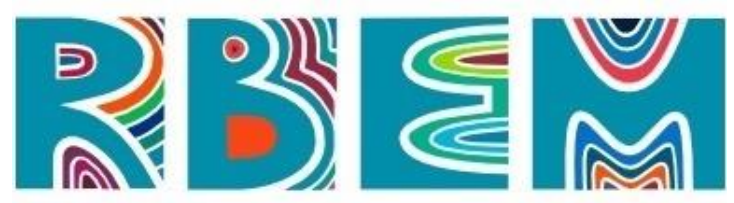

REVISTA BAIANA DE EDUCAÇÃO MATEMÁTICA

ECS, sem justificativa, ou ainda, receber a proposta de farsa do estágio, quando um responsável pela escola se dispõe a assinar o documento do estágio sem ele ter, de fato, ocorrido. Ademais, muitas vezes, o estagiário é restringido ao espaço da sala de aula, impossibilitado de conhecer a escola no seu dinamismo e riqueza de contradições, ou, ainda, solicitado a substituir professores (PICONEZ et al, 2012).

Há de se considerar, portanto, a formação de um profissional reflexivo, que consiste na capacidade de pensamento e reflexão que o caracteriza como um ser humano criativo e não como mero reprodutor de práticas que lhe são exteriores (ALARCÃO, 2011). A defesa por esse tipo de formação está para além de um estágio na perspectiva da prática pela prática ou da experiência pela experiência, algo puramente técnico, burocrático, sem a devida problematização e reflexão. É fundamental, pois, “projetos que valorizem a pesquisa, as práticas coletivas, colaborativas e reflexivas, tão favoráveis ao desenvolvimento profissional não apenas dos futuros professores, como também dos demais atores envolvidos nesse processo de formação" (SAKAI; PEREIRA, 2017, p. 114).

Independente das críticas ao estágio, à escola e ao sistema como um todo, é inegável a importância desse processo na formação inicial do professor, conforme relato encontrado em Freitas, Silva e Oliveira (2010, p. 68, grifo dos autores), “[...] foi muito gratificante, pois

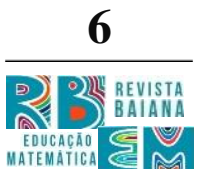
pude colocar em prática todos os conhecimentos adquiridos durante o curso de graduação". Nesse percurso, o papel do professor orientador do estágio é fundamental e deve ser, segundo Ribeiro (2012), o de mediador entre as agências formadoras e as instituições escolares, interagindo no sentido de conscientizar que os profissionais da escola têm parcela de responsabilidade na formação dos professores.

Nem sempre os professores da Educação Básica se percebem na condição de participantes do processo de formação dos estagiários. Entre os fatores, destaca-se o professor atarefado, que não tem condições de assumir mais uma responsabilidade para si e o desconhecimento da sua relevância no processo de ECS. Nesse sentido, Silva e Oliveira (2021) destacam a importância deste profissional compreender seu papel na formação do estagiário, de modo que ele não se sinta vigiado ou avaliado, mas como um elemento importante na formação, oportunizando experiências práticas e possibilidades que contribuirão para o crescimento dos estagiários. 


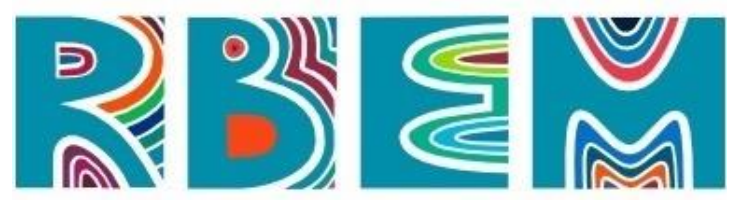

REVISTA BAIANA DE EDUCAÇÃO MATEMÁTICA

Retornando ao papel do professor orientador do estágio, não restam dúvidas de que deve ser um apoio, realmente, de orientação, de troca. $\mathrm{O}$ profissional deve acompanhar $\mathrm{o}$ estagiário, discutir estratégias de ensino, pesquisar e auxiliar na elaboração de atividades diferenciadas e pertinentes ao contexto do planejamento. Em Freitas, Silva e Oliveira (2010), encontra-se, por meio do relato de uma estagiária, uma prática que suscitou na própria acadêmica questionamentos sobre o verdadeiro papel desse profissional.

Ela tinha um roteiro pronto para nós estagiários. Tínhamos que ter os planos de aula impecáveis e aplicar o lúdico. A supervisão ofereceu maior atenção ao fato de eu ter meus planos de aula todos feitos e de forma correta. Pressentia que a preocupação dela era apenas em avaliar mais a parte estrutural dos planos de aula do que propriamente meus métodos de ensino (FREITAS; SILVA; OLIVEIRA, 2010, p. 66, grifo dos autores).

O excerto serve para levantar uma valiosa reflexão sobre o uso de metodologias, lúdicas ou não. A escolha da metodologia deve estar alinhada aos objetivos a serem desenvolvidos, e não simplesmente ao uso pelo uso, por isso é necessário conhecer, discutir e empregá-las, para posteriormente avaliar a eficiência no processo. Caso contrário, serão comuns relatos como o apresentado em Freitas, Silva e Oliveira (2010), em que a estagiária cita a cobrança pela aplicação do lúdico no Ensino Médio e, como desconhecia tais metodologias, não conseguiu cumprir a exigência do orientador.

Kulcsar (2012) debate o mérito de repensar o estágio, a escola e a universidade. O estágio precisa sempre ser um campo de estudos, questionamentos, um repensar mútuo e colaborativo no sentido de que ele não é isolado. É de relevância também pensar que ser professor é aprender a cada dia, no âmbito das relações e das trocas. De mais a mais, segundo Freire (1991), ninguém nasce educador e nem se torna educador numa terça-feira às $4 \mathrm{~h}$ da tarde, mas, sim, se faz educador permanentemente, através da prática e da reflexão.

\section{O percurso metodológico da produção e análise dos dados}

A abordagem metodológica é predominantemente qualitativa, considerando o exposto por Ludke e André (1986), quando apontam que investigações dessa natureza apresentam as seguintes características: ambiente natural como fonte direta de dados e o pesquisador como seu principal instrumento; os dados coletados são predominantemente descritivos; a 


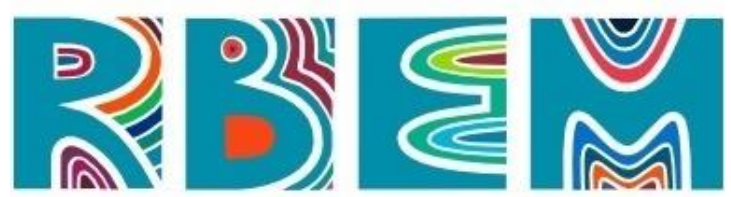

REVISTA BAIANA DE EDUCAÇÃO MATEMÁTICA

preocupação com o processo é muito maior do que com o produto; o significado que as pessoas dão às coisas e à sua vida é foco de atenção especial pelo pesquisador; a análise dos dados tende a seguir um processo indutivo.

Nessa perspectiva, foram aplicados dois questionários, que, conforme Gil (2012), são a técnica de investigação composta por um conjunto de questões, às quais os participantes da pesquisa são submetidos, a fim de obter informações sobre crenças, sentimentos, valores, entre outros. Os questionários foram aplicados a quinze (15) acadêmicos do curso de Licenciatura em Matemática de uma universidade pública que, no segundo semestre de 2019, realizaram o denominado ECS, desenvolvido nos Anos Finais do Ensino Fundamental. Tais estagiários foram identificados pelas letras do alfabeto, por exemplo: Estagiário A, Estagiário B e, assim, sucessivamente, para fins de pesquisa.

O Quadro 1 apresenta, na primeira coluna, o questionário inicial, o qual denominamos de pré-estágio, composto de duas questões abertas, aplicado antes do início da prática da componente curricular. A segunda coluna apresenta o questionário pós-estágio, composto de três questões abertas, respondido pelos acadêmicos ao final da prática, a partir das respostas dadas no primeiro questionário. O questionário final, além de confrontar as respostas, perguntou sobre as aprendizagens construídas ao longo do processo de estágio. Ambos os questionários foram aplicados com o objetivo de promover a reflexão acerca da prática de estágio curricular, bem como produzir dados para análise.

Quadro 1: questionário pré-estágio e pós-estágio

\begin{tabular}{|l|ll|}
\hline Questionário 1 (pré-estágio) & Questionário 2 (pós-estágio) \\
\hline 1) Quais as perspectivas em relação ao & 1) As perspectivas foram atendidas? \\
$\begin{array}{l}\text { estágio? } \\
\text { 2) Quais os desafios a serem enfrentados? }\end{array}$ & 2) Os desafios foram superados? Justifique \\
Justifique. & 3) O que você aprendeu com este estágio? \\
\hline
\end{tabular}

Fonte: Autores (2021)

Para apresentar e analisar as respostas produzidas por meio dos questionários, foram utilizadas as nuvens de palavras, geradas no Software WordArt ${ }^{1}$. As nuvens de palavras, segundo destacam Borba, Almeida e Gracias (2018), são uma técnica nova, na qual é difícil

1 https://wordart.com/ 


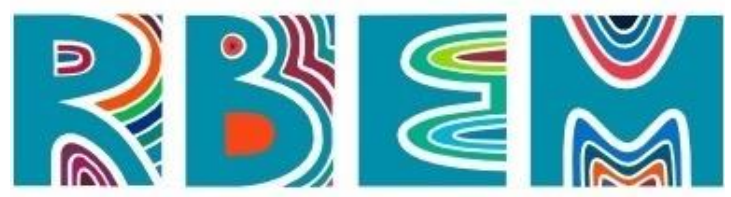

REVISTA BAIANA DE EDUCAÇÃO MATEMÁTICA

diferenciar o qualitativo do quantitativo. Além disso, ressalta-se que ela apresenta em destaque as palavras que aparecem com mais frequência no texto. Assim, consoante os autores, "podemos partir de uma ferramenta quantitativa e lançar um olhar qualitativo" (BORBA; ALMEIDA; GRACIAS, 2018, p. 79).

Também foi realizada uma análise documental, que, de acordo com Gil (2012), vale-se de materiais que ainda não receberam tratamento analítico. Os documentos analisados foram os portfólios, definidos por Alarcão (2011, p. 60) como "um conjunto coerente de documentação refletidamente selecionada, significativamente comentada e sistematicamente organizada e contextualizada no tempo, reveladora do percurso profissional". Os portfólios foram construídos pelos estudantes ao longo do estágio, devendo conter as melhores amostras do trabalho em forma de imagens, anotações pessoais, experiências de aula, representações que proporcionem refletir sobre o processo do estágio.

A ideia de trabalhar com os portfólios, em que os estudantes registraram de forma reflexiva as atividades realizadas a cada duas semanas, tem base no exposto por Jaramillo (2003). Para a autora, há instrumentos de mediação que permitem desencadear processos metacognitivos e metareflexivos, entre eles: diário reflexivo, mapas conceituais, autobiografia, entre outros. Nesse sentido, os portfólios foram empregados visando favorecer a reflexão sobre a prática, os quais, posteriormente, servirão também como dados para pesquisa, permitindo a triangulação com os questionários.

\section{Resultados e discussões}

O ECS, segundo Valverde (2005), é o momento em que o aluno vivencia a realidade da escola em toda a sua complexidade, os problemas a serem enfrentados, analisando seu funcionamento, sua rotina e organização, sendo um momento difícil e de tomada de decisões. Tendo em vista o exposto e acrescentando que o momento poderá ser um marco definitivo na história profissional, esse ECS foi planejado, organizado e realizado. Além da atenção e dos cuidados empregados, foram utilizados instrumentos de reflexão e produção de dados. No concernente aos questionários e ao portfólio virtual, ambos serão discutidos na sequência.

A princípio, foi solicitado aos estagiários que respondessem o questionário inicial. No primeiro questionamento, sobre as perspectivas em relação ao estágio, citaram que a principal 


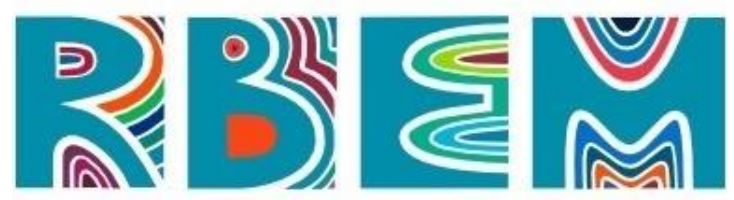

REVISTA BAIANA DE EDUCAÇÃO MATEMÁTICA

delas é o aluno da Educação Básica aprender matemática. Logo após, aparece a utilização de diferentes metodologias e, com o mesmo número de ocorrências, aparece uma boa relação com os alunos, entre outras, conforme mostra a nuvem de palavras, Figura 1.

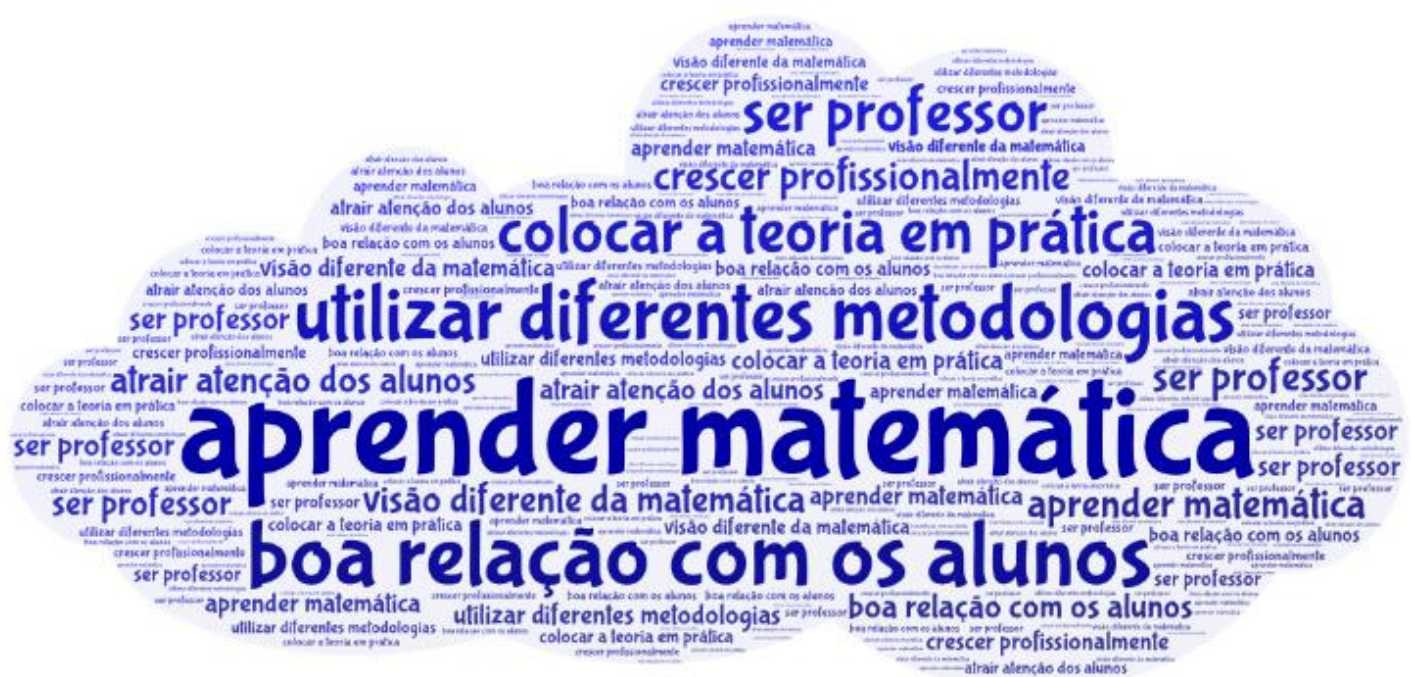

Figura 1: Nuvem de palavra com as respostas dos estagiários sobre a pergunta: quais as perspectivas em relação ao estágio? (AUTORES, 2021).

A aprendizagem da Matemática não é um desafio só para os estagiários, é também para os professores, inclusive para aqueles com experiência, gestores educacionais e e governantes, tamanha a complexidade e as circunstâncias envoltas. Van de Walle (2009) expõe que a maioria das pessoas sabe que a Matemática é importante, mas poucos compreendem do que trata, pois, em geral, resumem-na a um conjunto de regras, de cálculos, a serem memorizados e reproduzidos. Ademais, segundo Van de Walle (2009), Borba, Almeida e Gracias (2018), é comum indivíduos expressarem de maneira orgulhosa depoimentos a respeito de não terem aprendido Matemática na escola.

Embora a aprendizagem Matemática não seja o foco do artigo, é de relevância na formação do professor e deve suscitar atenção em prol de resultados mais significativos. Na verdade, quanto ao que o professor precisa considerar para uma efetiva aprendizagem, Pires destaca: "Não resta dúvida, saber o conteúdo para si mesmo não é suficiente, é preciso saber como fazer o conteúdo atingir o aluno, ou seja, interessá-lo, envolvê-lo e mostrar que nada pode ser tão difícil, que não se aprenda com algum tempo e dedicação" (2012, p. 232).

A citação de Pires, reflexões de um estagiário, traz uma preocupação no sentido de como desenvolver a aula para que o aluno aprenda. Essa é uma preocupação dos participantes 


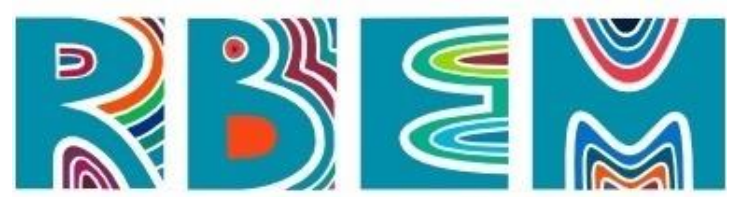

REVISTA BAIANA DE EDUCAÇÃO MATEMÁTICA

desta pesquisa, já que a nuvem traz em destaque, também, utilizar diferentes metodologias. Conforme salienta Felcher et al (2017), é fulcral repensar a metodologia adotada pelo professor, que geralmente se debruça a apresentar conceitos, resolver exemplos e solicitar a realização de listas de exercícios, um processo mecânico que exige apenas a reprodução dos conceitos trabalhados.

Para Van de Valle (2009), por mais que o professor seja claro nas suas explicações e o faça inúmeras vezes, não garante a aprendizagem dos estudantes. Consoante o autor, a aprendizagem é um processo que ocorre na mente de cada um como resultado do envolvimento ativo nas propostas de aprendizagem. $\mathrm{O}$ exposto pelo autor vem reforçar a necessidade de romper com práticas mecânicas e oportunizar a construção do conhecimento pelo estudante, mediado pelo professor.

Posteriormente, os estagiários foram perguntados se as perspectivas foram atendidas. Treze (13) deles disseram que sim e dois (2) citaram que as perspectivas foram parcialmente atendidas. Entre os que citaram sim, aparecem diversos fatores como justificativa. Entre outros, encontra-se o fato de que os alunos foram tornando-se mais participativos, gostando das aulas, o que foi proporcionando uma melhor relação aluno e professor, que, somada à utilização de metodologias diferenciadas, resultou no envolvimento dos estudantes e em um sentimento de confiança na escolha profissional. Salienta-se a seguinte resposta ${ }^{2}$ :

O estágio superou todas as minhas expectativas. A turma se dedicou muito e eu pude perceber que eles apreciaram as aulas de Matemática, porque esperavam ansiosos pelas próximas aulas. Claro que as vezes não estavam empolgados em fazer as atividades. Mas, na maioria das vezes eles se dedicaram e era nítido que começaram a gostar mais das aulas de Matemática (Estagiário E).

Os estagiários que responderam que as perspectivas foram parcialmente atendidas, mencionaram a pouca vontade do aluno em aprender Matemática: “A desmotivação dos alunos no início do estágio em relação as propostas era absoluta em sala de aula. Porém, ao se utilizar de jogos e resoluções de problemas a vontade de aprender foi mais percebida e relevante com a maioria" (Estagiário A). A desmotivação de parcela significativa dos estudantes é uma realidade e aparece muito fortemente em relatos citados em Freitas, Silva e Oliveira (2010, p. 67):

\footnotetext{
${ }^{2}$ Os recortes analisados comportam a transcrição diplomática das respostas dos estagiários ao questionário. Ou seja, não houve nenhuma modificação/alteração no texto.
} 


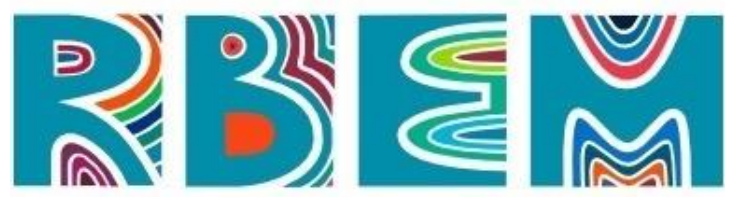

REVISTA BAIANA DE EDUCAÇÃO MATEMÁTICA

Pude perceber que nem sempre os alunos estão interessados em aprender. Alguns estão nas salas de aula apenas por obrigação ou porque os pais querem que estejam ali. Mesmo com alunos desmotivados nunca deixei de acreditar no potencial de cada um e sempre tentando buscar o melhor, incentivando e conversando sobre a profissão que eles estavam escolhendo naquele momento.

Quando perguntados sobre os desafios a serem enfrentados no estágio, os acadêmicos, na maioria das respostas, trouxeram fatores relacionados a si próprios, embora em menor grau apareçam, também, fatores relacionados ao aluno, a professores, à instituição e inclusive ao contexto social, conforme Figura 2.

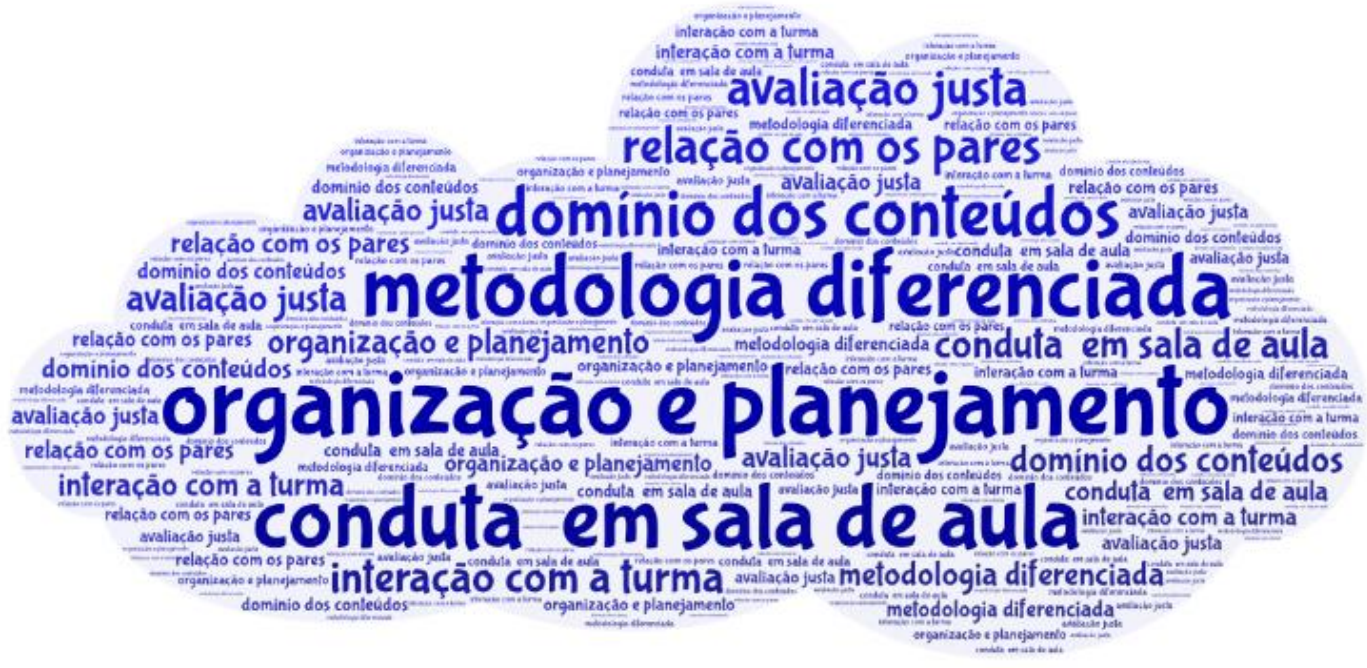

Figura 2: Nuvem de palavra com as respostas dos estagiários sobre a pergunta: Quais os desafios a serem enfrentados no estágio? (AUTORES, 2021).

A organização e o planejamento são essenciais para o êxito de qualquer atividade e não poderia ser diferente quando a pauta são os processos de ensino e aprendizagem. Van de Walle (2009) sublinha que mesmo os professores experientes precisam dar atenção ao planejamento, pois toda turma é diferente e isso precisa ser considerado. Segundo o autor, as escolhas das tarefas e como elas devem ser apresentadas devem ser feitas diariamente para se ajustarem às necessidades dos estudantes. Insta dizer que o planejamento deve ser dinâmico, sofrendo mudanças quando necessário em prol de efetivas aprendizagens.

De mais a mais, aparecem alguns fatores como fundamentais para o sucesso do estágio que não estão atrelados ao estagiário, conforme Figura 3. 


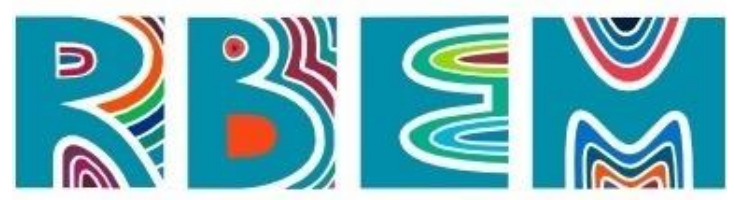

REVISTA BAIANA DE EDUCAÇÃO MATEMÁTICA

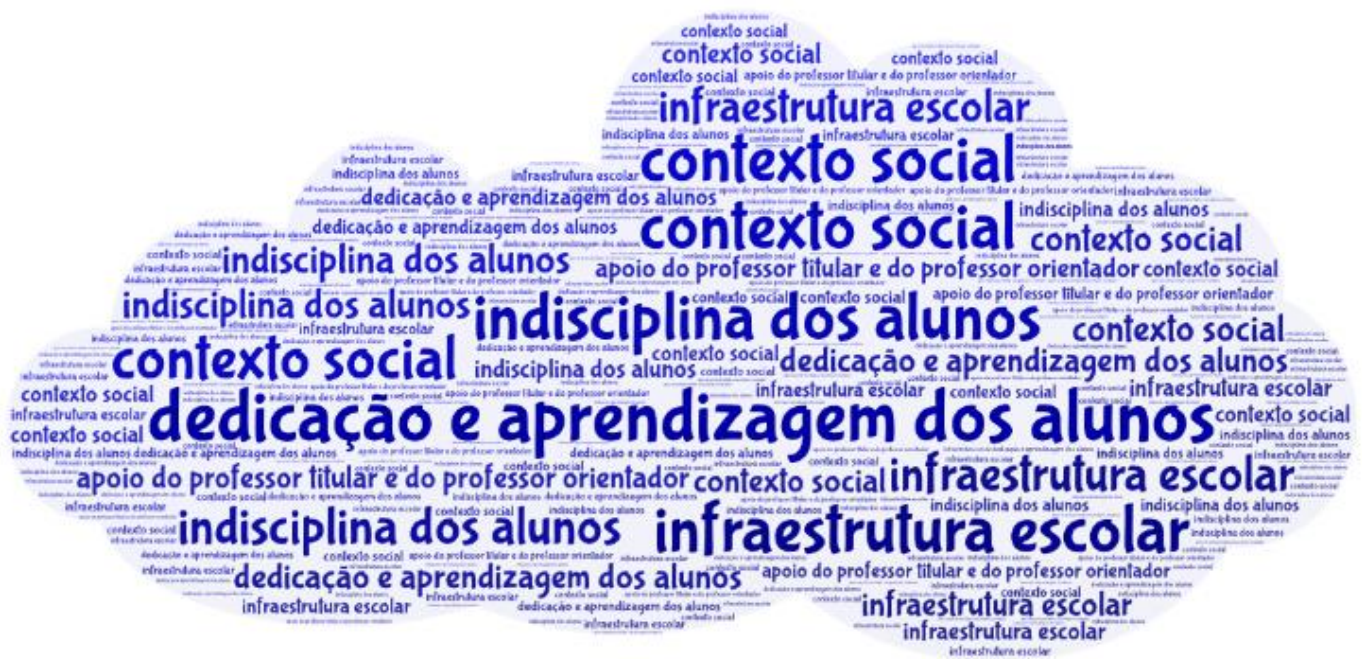

Figura 3: Nuvem de palavra com as respostas dos estagiários sobre a pergunta: Quais os desafios a serem enfrentados no estágio? (AUTORES, 2021).

Segundo Tardif (2002, p. 167), “ensinar é entrar numa sala de aula e colocar-se diante de um grupo de alunos, esforçando-se para desencadear com eles um processo de formação mediado por uma grande variedade de interações". No entanto, em certas situações, embora o esforço e a dedicação do professor, a aprendizagem não acontece, pois ele está condicionado a uma série de fatores. A propósito, um fator que pode ser prejudicial à aprendizagem é a indisciplina dos alunos, destaque na nuvem, como um desafio a ser enfrentado.

Ao citar a indisciplina dos estudantes como um desafio a ser superado, os estagiários trazem para a pauta um tema que merece atenção e que não é uma preocupação específica deles. Em Fillos e Marcon (2011, p. 1696) encontra-se: “[...] tive vontade de desistir porque me decepcionei muito com o que presenciei nas escolas, principalmente com relação à falta de educação dos alunos em sala de aula”. Porém, a disciplina não é um problema que atinge só estagiários, mas os professores de um modo geral, muitas vezes trazendo consequências para a aprendizagem e fazendo com que alterações curriculares sejam pensadas.

De posse de tais respostas, os acadêmicos foram perguntados se os desafios haviam sido superados e responderam que sim. Os estagiários justificaram que os discentes aprenderam os conceitos trabalhados, bem como os conhecimentos que eles próprios adquiriram ao longo da prática de estágio. Mas salientaram que gostariam de ter desenvolvido um número maior de atividades diferenciadas em sala de aula (as atividades desenvolvidas 


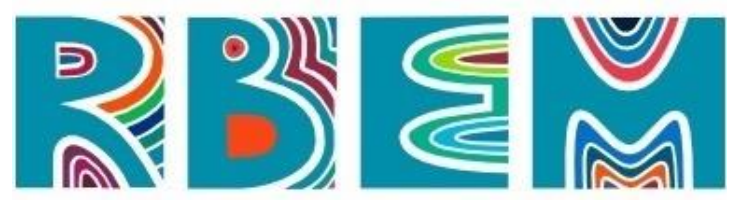

REVISTA BAIANA DE EDUCAÇÃO MATEMÁTICA

pelos estagiários serão citadas no decorrer do texto). Acrescentaram que o desinteresse por parte de certos alunos é um fator preocupante, porque, em determinados momentos, prejudica o andamento da aula e impossibilita o estagiário de desenvolver o planejamento com êxito.

A última questão, apresentada no segundo questionário, pós-estágio, perguntava sobre o que o estagiário havia aprendido com o estágio. Com maior ocorrência, aparece lidar com imprevistos, seguido de melhorar os planejamentos, considerar as diversidades, ter paciência, empregar diferentes metodologias, entre outros.

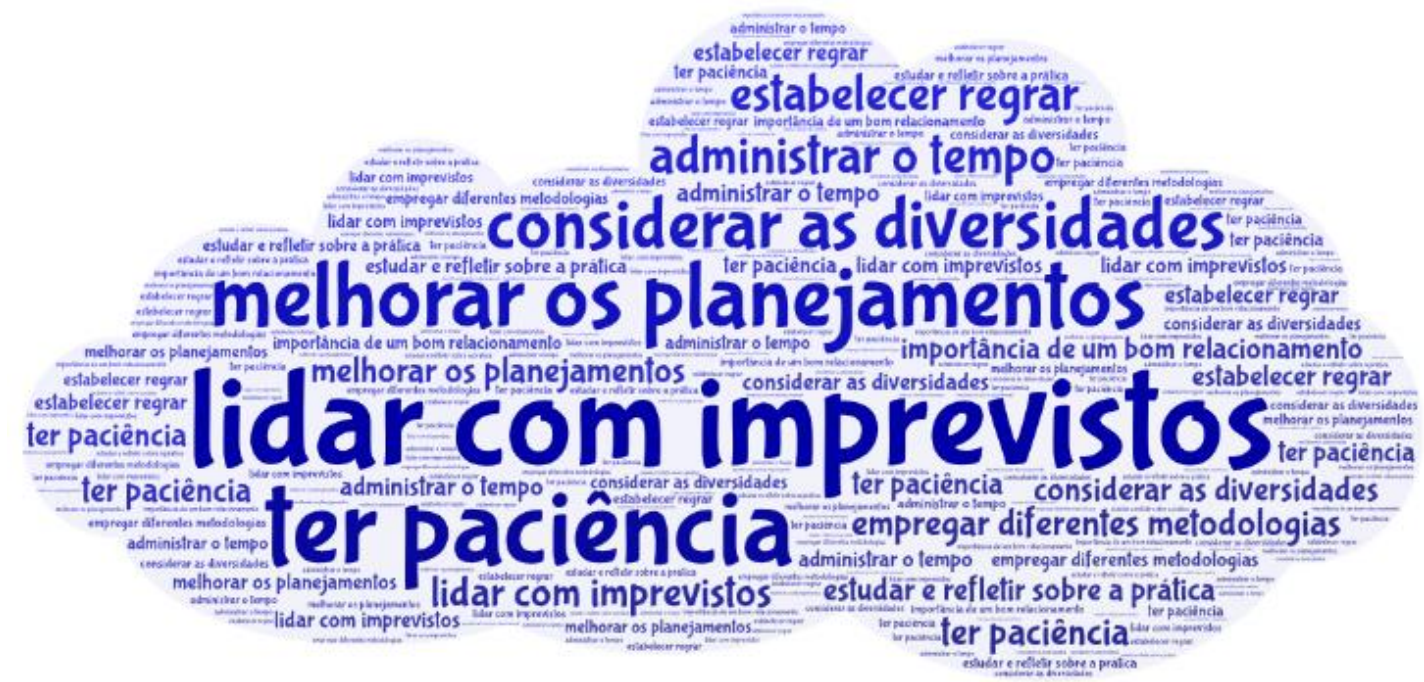

Figura 4: nuvem de palavra com as respostas dos estagiários sobre a pergunta: o que você aprendeu com este estágio? (AUTORES, 2021).

Em se tratando de lidar com os imprevistos, os estagiários alegam as situações inesperadas do dia a dia na escola. Por exemplo, a necessidade de desenvolver o dobro de aulas do que o previsto, ter dois ou três alunos apenas em sala de aula, adiar o início do planejamento referente a um conceito novo ou a data da prova, entre outros. Nesse sentido, o participante da pesquisa realizada por Valverde, cita: “[...] Assumir uma sala de aula não é tão simples como me parecia antes, envolve muita coisa, não é só chegar lá e dar aula" (2005, p. $60)$.

Certamente, ser professor vai muito além de ministrar aulas, é preciso conhecer, considerar e flexibilizar o processo em prol dos imprevistos e da qualidade da educação. " $U m$ dos grandes problemas enfrentados para que o estágio ganhe um ritmo e continue nesse 


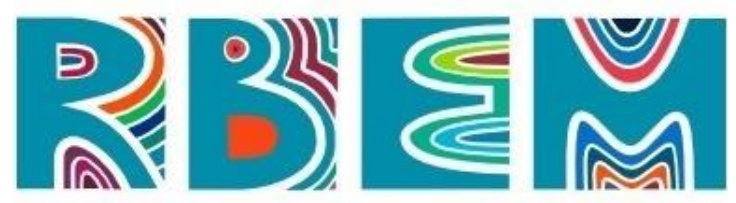

REVISTA BAIANA DE EDUCAÇÃO MATEMÁTICA

ritmo tem sido a questão climática, uma vez que chove, ou tem previsão de chuva os alunos não comparecem as aulas [...] e com isso não consigo dar sequência no conteúdo" (portfólio Estagiário J).

O registro da acadêmica fortalece a afirmativa de que a prática do estágio é fundamental para conhecer o interior das escolas. Para Pontes (2002), é essencial conhecer o modo como as escolas funcionam e criar confiança no seu relacionamento com os diversos atores educativos, considerando a análise dos aspectos problemáticos da atividade escolar e procurando estimular o empenho dos estudantes na respectiva transformação. Desse modo, frisa-se o quão pode ser significativa essa relação, a partir de fragmentos extraídos dos portfólios dos estagiários:

Mas o mais gratificante além dos resultados positivos obtidos pela maioria dos alunos, foi sem dúvida ouvir dos mesmos que gostavam da minha aula, que agora estavam entendendo a matéria, que iriam sentir minha falta e falta das minhas aulas (portfólio do Estagiário J)

O aprendizado no estágio é bárbaro, aprendemos com tudo e com todos, as situações enfrentadas, aulas diferenciadas, dúvidas dos alunos, pequenos detalhes já são imensamente contribuintes para nossa formação. A vivência dentro da escola, com os colegas de profissão, o ambiente escolar, a troca de experiências, e o envolvimento com os alunos já é uma aprendizagem notória na formação (portfólio do Estagiário G)

A ideia trazida pelos registros é relevante e singular para a escolha profissional e, segundo Medeiros (2010), poderá ser responsável pela colocação desses licenciandos no mercado de trabalho, haja vista que tem a capacidade de proporcionar o encantamento pela profissão, ou seja, formar um elo do que é ser professor. É nesse momento que tem uma compreensão mais inequívoca acerca da docência.

Revisitando as nuvens de palavras (Figura 2 e 4), constata-se uma maior visibilidade das metodologias diferenciadas. Isso é registrado no portfólio dos estagiários $\mathrm{G}$ e $\mathrm{O}$ respectivamente: "[...] meus alunos gostavam de aulas tradicionais", ou ainda, "[...] meus alunos não gostavam de jogos". Os registros servem de pano de fundo para questionamentos e discussões a respeito do porquê os estudantes preferem aulas tradicionais. Ademais, é preciso pensar que, além de jogos, existem possibilidades de outras metodologias para o ensino de Matemática. 


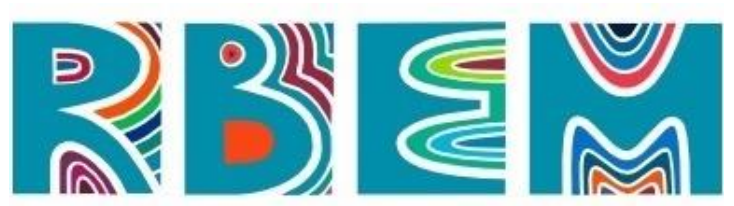

REVISTA BAIANA DE EDUCAÇÃO MATEMÁTICA

A Matemática é, sem dúvidas, um terreno fértil e propício para a utilização de diferentes metodologias. A Figura 5 traz recortes dos portfólios dos estagiários, evidenciando a utilização das tecnologias digitais (Código QR e aplicativo Photomath), jogos didáticos (Boole, dominó e batalha naval) e materiais concretos (dobradura e geoplano). Essas são algumas das possibilidades, visto que há espaço para investigações matemáticas, História da Matemática, Modelagem Matemática, Resolução de problemas, entre outros. Por meio da resolução de problemas, afirma Van de Walle (2009), a maioria, se não todos, dos conceitos matemáticos podem ser ensinados.

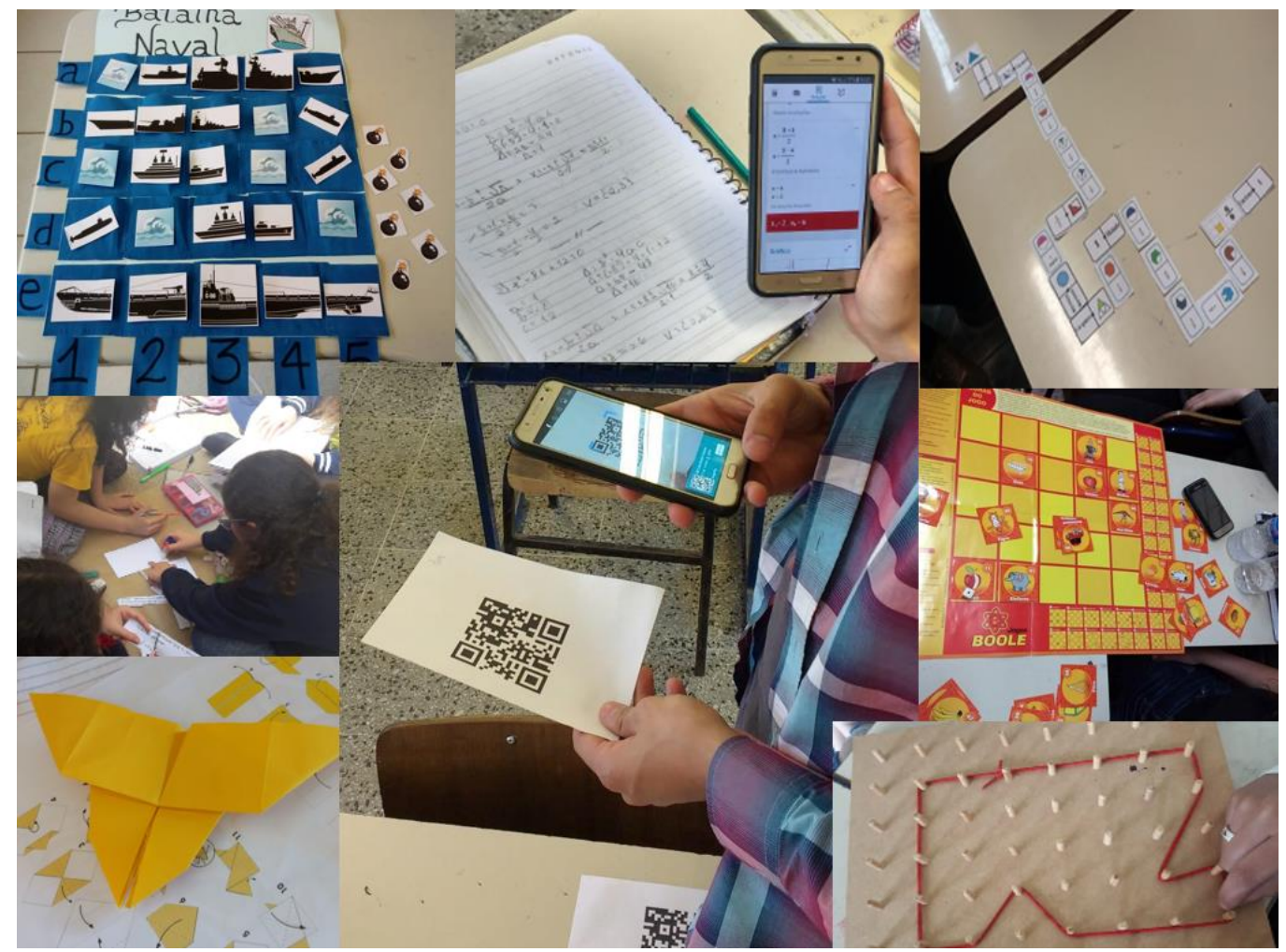

Figura 5: Atividades desenvolvidas pelos estagiários (AUTORES, 2021).

A escolha por determinada metodologia deve estar relacionada aos objetivos referentes ao ensino e à aprendizagem, às possibilidades que se tem e ao perfil dos envolvidos, uma vez que o uso de determinada metodologia não é sinônimo de resultado em termos de aprendizagem. A forma com que será utilizada, atrelada a um contexto específico e às interações proporcionadas, é que poderá ou não contribuir para o processo de aprendizagem. 


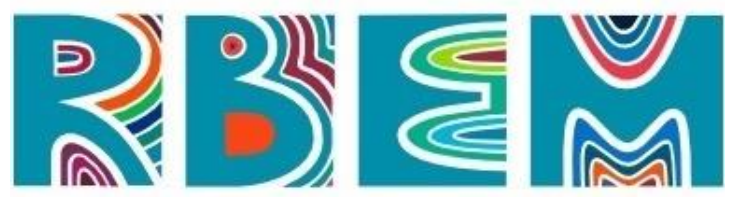

REVISTA BAIANA DE EDUCAÇÃO MATEMÁTICA

Nesse sentido, deseja-se utilizar as tecnologias para transformar, não para reproduzir práticas tradicionais consagradas.

Adorei as aulas em que apliquei os jogos, pois os alunos saiam daquele clima "senta e copia", era um momento de aprendizado e também de muita alegria. Os alunos adoravam. Esse primeiro estágio me surpreendeu muito. Estou muito feliz com tudo o que pude vivenciar em sala de aula: os momentos de muita alegria e os momentos mais complicadinhos, que serviram de aprendizado também (portfólio estagiário E).

Concluindo este trabalho pude ver a importância do uso de diferentes metodologias para o ensino de Matemática. Este torna a aula mais prazerosa e instigante, pois pode mostrar uma diferente visão que talvez apenas pelo método tradicional não se conseguiria alcançar e qualifica o ensino da Matemática (portfólio estagiário D).

Logo, os relatos anteriores são animadores quanto à importância e aos resultados positivos da experiência dos estagiários, tanto no sentido de satisfação pelo trabalho realizado, quanto pelas aprendizagens construídas. Jaramillo (2003) enfatiza a importância de repensar os modelos tradicionais de formação de professor. Segundo a autora, as formações precisam oportunizar a cada licenciando chegar a ser professor de Matemática através de um caminho, no qual riscos precisam ser assumidos, tendo em vista uma apropriação mais consciente da complexidade da prática docente.

\section{Considerações finais}

O ECS é fundamental na formação do professor, pois é um momento que vai além de pôr em prática os conhecimentos adquiridos ao longo da licenciatura. É o momento de ampliar os conhecimentos, ressignificar, contestar, experimentar novas metodologias alinhadas ao currículo, (re)planejar a sala de aula. Em outras palavras, por meio de um processo de reflexão, aprender cada vez mais. Acredita-se que o portfólio neste ECS tenha contribuído amplamente para a reflexão, já que, quinzenalmente, o estagiário relatava, através de textos e imagens, o período de estágio.

Os questionários e os portfólios apontam que a expectativa era que os alunos aprendessem Matemática, o que, segundo eles, aconteceu. E, mesmo em turmas consideradas desmotivadas, o interesse e a participação foram gradativamente aumentando. Em relação aos desafios, o maior deles era a organização e o planejamento, superados com êxito. Uma das aprendizagens citadas foi lidar com os imprevistos. Em resumo, o ECS foi significativo e de grande aprendizagem para os estagiários, que reafirmam o desejo de ser professor. 


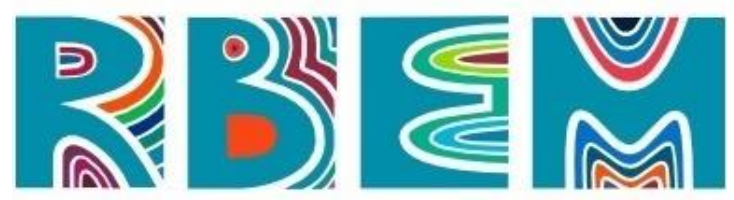

REVISTA BAIANA DE EDUCAÇÃO MATEMÁTICA

Por fim, retomando as expectativas e os desafios referente ao ECS, é evidente que sempre farão parte do processo, o qual é complexo, único e permeado de descobertas. O importante é que sirvam para impulsionar o crescimento dos estagiários e sejam considerados por todos aqueles que contribuem com/para a formação de professores, por intermédio da prática pedagógica, das ações ou falas cotidianas. Desse modo, o ECS será cada vez mais um momento de aprendizagem, de reflexão e de ressignificação do aprendido, como aconteceu com os estagiários participantes desta investigação.

\section{Referências}

ALARCÃO, I. Professores reflexivos em uma escola reflexiva. São Paulo: Cortez, 2011.

BORBA, M. C; ALMEIDA, H. R. F. L; GRACIAS, T. A. S. Pesquisa em ensino e sala de aula: diferentes vozes em uma investigação. Belo Horizonte: Autêntica, 2018.

BRASIL. Lei $n^{\circ}$ 9.394, de 20 de dezembro de 1996. Estabelece as diretrizes e bases da educação nacional. Diário Oficial da União, Brasília, 23 dez. 1996, Seção 1, p. 1-9.

Disponível em http://www.planalto.gov.br/ccivil_03/LEIS/L9394.htm. Acesso em: 15 jul. 2021.

BRASIL. Resolução CNE/CP 2/2015. Define as Diretrizes Curriculares Nacionais para a formação inicial em nível superior (cursos de licenciatura, cursos de formação pedagógica para graduados e cursos de segunda licenciatura) e para a formação continuada. Diário Oficial da União, Brasília, 2 jul. 2005, Seção 1, p. 8-12. Disponível em:

http://portal.mec.gov.br/docman/agosto-2017-pdf/70431-res-cne-cp-002-03072015-pdf/file. Acesso em: 11 jul. 2021.

CYRINO, M.C.C.T.; PASSERINI, G.A. Reflexões sobre o estágio supervisionado do curso de Licenciatura em Matemática da Universidade Estadual de Londrina. In: CAINELLI, M.; FIORELI, I. (Org.). O estágio na licenciatura: a formação de professores e a experiência interdisciplinar na Universidade Estadual de Londrina. Londrina: UEL Prodocencia Midiograf, 2009, p. 125-144.

FAZENDA, I. C. A. O papel dos estágios nos cursos de formação de professores. In: PICONEZ, S. C. B (Coord.) et al. A prática de ensino e o estágio supervisionado. Campinas/SP: Papirus, 2012.

FELCHER, C. D. O et al. Produzindo vídeos, construindo conhecimento: uma investigação com acadêmicos da Matemática da Universidade Aberta do Brasil. In: Revista Educacional Interdisciplinar, v. 6, n. 1, 2017. 


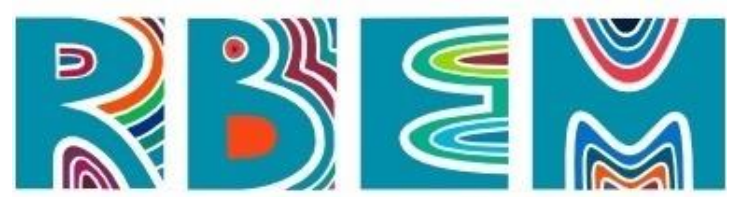

REVISTA BAIANA DE EDUCAÇÃO MATEMÁTICA

FILLOS, L. M; MARCON, L. C. J. Estágio Supervisionado em Matemática: significados e saberes sobre a profissão docente. Anais do X Congresso Nacional de Educação EDUCERE. 2011.

FIORENTINI, D. Em busca de novos caminhos e de outros olhares na formação do professor de Matemática. In.: FIONTENTINI, D. (Org.). Formação de professores de Matemática. Campinas: Mercado das Letras, 2003.

FIORENTINI, D.; CASTRO, F. C. Tornando-se professor de Matemática: o caso de Allan em prática de ensino e estágio supervisionado. In.: FIONTENTINI, D. (Org.). Formação de professores de Matemática. Campinas: Mercado das Letras, 2003.

FREIRE, P. A Educação na cidade. São Paulo, Cortez, 1991.

FREITAS, M. T. M. et al. O desafio de ser professor de Matemática hoje no Brasil. In.: FIORENTINI, D.; NACARATO, A. M. Cultura, formação e desenvolvimento profissional de professores que ensinam Matemática. São Paulo: Musa Editora, 2005.

FREITAS, Fabrício Monte; SILVA, João Alberto da; OLIVEIRA, Ricardo Rios. Formação inicial de professores de matemática: os estágios supervisionados e as histórias de vida. Revista Revemat. Florianópolis, v. 5, n. 1, p. 61-70, 2010.

GATTI, B. A.; SÁ BARRETO, E. S. de. Professores do Brasil: impasses e desafios. Brasília: UNESCO, 2009.

GIL, A. C. Métodos e Técnicas de Pesquisa Social. 6. ed. São Paulo: Atlas, 2012.

KULCSAR, R. O estágio supervisionado como atividade integradora. In: PICONEZ, S. C. B (Coord.) et al. A prática de ensino e o estágio supervisionado. Campinas/SP: Papirus, 2012.

JARAMILLO, D. Processos metacognitivos na (re)constituição do ideário pedagógico de licenciandos em Matemática. In.: FIONTENTINI, D. (Org.). Formação de professores de Matemática. Campinas: Mercado das Letras, 2003.

LOPES, A. R. L. V. et al. Estágio Curricular Supervisionado nas licenciaturas em Matemática: reflexões sobre as pesquisas brasileiras. Zetetike, v. 25, n. 1, p. 75-93, 2017.

LÜDKE, M.; ANDRÉ, M. A pesquisa em educação: abordagens qualitativas. São Paulo: EPU, 1986.

MEDEIROS, C. M. Estágio Supervisionado: uma influência na constituição dos saberes e do professor de matemática na formação inicial. Dissertação (Mestrado em Educação e em Ciências e Matemática). UFPA. Belém, 2010. 


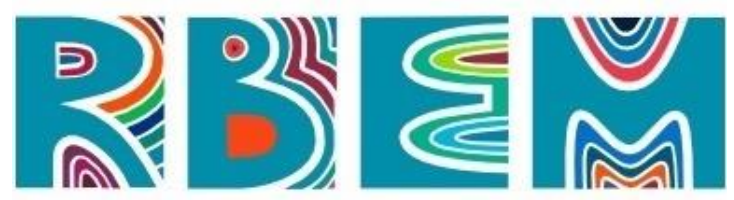

REVISTA BAIANA DE EDUCAÇÃO MATEMÁTICA

PIRES, M. A. L. M. Um estudo sobre o estágio supervisionado na formação inicial de professores de Matemática na Bahia. Tese (Doutorado em Educação Matemática e Ensino de Ciências). UFRN, Natal, 2012.

PICONEZ, S. C. B. A prática de ensino e o estágio supervisionado: a aproximação da realidade escolar e a prática da reflexão. In: PICONEZ, S. C. B (Coord.) et al. A prática de ensino e o estágio supervisionado. Campinas (SP): Papirus, 2012.

PONTE, J. P. et al. Por uma formação Inicial de professores de qualidade. Documento de trabalho da Comissão ad hoc do CRUP para a formação de professores. 2000.

www.educ.fc.ul.pt/docentes/jponte/docs-pt/00-Ponte-etc(CRUP).doc. Acesso em: 20 jun. 2021.

PONTE, J. P. A vertente profissional da formação inicial de professores de matemática. 2002. Disponível: http://www.educ.fc.ul.pt/docentes/jponte/docs-pt/02-

Ponte\%20(SBEM).pdf. Acesso em: 25 nov. 2018.

RIBEIRO, M. L. S. Educação Especial: desafio de garantir igualdade aos diferentes. In: PICONEZ, S. C. B (Coord.) et al. A prática de ensino e o estágio supervisionado. Campinas (SP): Papirus, 2012.

SAKAI, E. C. T; PEREIRA, P. S. Dialogando com as modalidades de práticas de estágio supervisionado em Matemática. Revista Paranaense de educação Matemática. RPEM, Campo Mourão, PR, v. 6, n.10, p. 90-117, jan.-jun., 2017.

SBEM. Sociedade Brasileira de Educação Matemática. Subsídios para a discussão de propostas para os cursos de Licenciatura em Matemática: uma contribuição da Sociedade Brasileira de Educação Matemática. Brasília, 2013.

SILVA, U. D.; OLIVEIRA, A. T. C. C. Influências do Estágio Supervisionado para Professores de Matemática em Início de Carreira-buscando compreender escolhas e características das escolas-campo. Revista Baiana de Educação Matemática, v. 2, n. 1, p. e202101-e202101, 2021.

TARDIF, M. Saberes docentes e formação profissional. Petrópolis (RJ): Vozes, 2002.

VALVERDE, L. P. A Experiência do Estágio Supervisionado para alunas de um curso Normal: algumas contribuições para a Formação de Educadores. Dissertação (Mestrado em Ensino, Filosofia e História das Ciências). UFBA. Salvador, 2005.

VAN DE WALLE, J. A. Matemática no ensino fundamental: formação de professores e aplicação na sala de aula. Porto Alegre: Artmed, 2009.

Artigo submetido em: 30/07/2021

Artigo aceito em: 20/08/2021 